\title{
Research on the Innovation Ability of PE Teaching under the Multi Objective Dynamic Condition
}

\author{
Xiao-long Bai* \\ Sports Department, Xinjiang Agricultural Vocational and Technical College, Changji, China. \\ baixiaolong0116@sina.com, *corresponding author
}

\begin{abstract}
Keywords: Physical Education Teaching, Multi Objective, System Dynamics
\end{abstract}
\begin{abstract}
With the continuous refinement of the education system and the improvement of the requirements of the innovation ability of the discipline is becoming higher and higher. In this paper, the sports teaching innovation ability is studied, through the impact of sports innovation capacity of multiple objectives are summarized, the use of system dynamics model for dynamic analysis of sports innovation capacity. Finally build the sports teaching innovation ability system dynamics model.
\end{abstract}

\section{Introduction}

From the establishment of sports major to the present, from the single curriculum development to many courses, professional sports teaching. With the continuous deepening of education reform and the requirements of the new curriculum reform, the sports teaching system and gradually tend to be standardized. Sports education in Colleges and Universities of physical education has been developing to the systematization, opening and development. However, with the continuous improvement of the sports education market, the sports teaching talent gap gradually narrowed. At present, PE teachers through the sports course teaching to spread the knowledge [1], many sports teachers teaching in physical education is completely in accordance with their own knowledge and experience to carry on the teaching, they serve as a knowledge transfer rather than innovators. To a large extent, the physical education teachers are very dependent on the mode of physical education, which has a direct impact on the actual implementation of physical education teaching in the size of the loyalty of the curriculum model [2].

Since twentieth Century, in order to deal with the global issues of technological innovation, population explosion and environmental pollution, for the sustainable development of human beings, all countries in the world began education innovation, hope to solve all kinds of problems through educational innovation. Many schools also made a lot of sports courses in the field of mode [3-4]. Since 2001, China carried out several education curriculum reform, the country's "three grade curriculum management system has been based on the" curriculum standards "under the framework of the physical education curriculum mode provides policy support. But for now, the sport teaching mode is still following the traditional one.

Therefore, through the research on the innovation ability of physical education teaching, we can sum up a lot of problems in the innovation of physical education teaching, and have profound significance for the innovation of physical education curriculum and teaching in China.

\section{Factors Affecting the Innovation Ability of Physical Education Teaching}

There are many factors that affect the innovation ability of PE teaching, so the main factors are analyzed here.

Financial Support. Innovation research cannot be separated from the financial support, the number of funds directly affect the course of the course innovation ability. The main factors that affect the innovation ability of physical education teaching include: research infrastructure, university research funds, government funds investment, financial institution loans and Innovation achievement conversion rate [5]. The transformation of innovation achievements, can affect the government's understanding of the subject and the recognition of scientific research results, and 
increase research investment, while the factors also affect the research loan. If the teaching innovation ability is strong, the university inside through its own funds to strengthen the input of the course.

Scientific Research Personnel. The number of scientific research personnel and the ability of researchers will affect the innovation ability of physical education teaching. Here, it is assumed that the scientific research personnel engaged in the teaching of physical education innovation mainly come from the key universities and some social research personnel. Social scientific research personnel are restricted by the general population. Key university graduates are affected by the results of the innovation of physical education; some of them are engaged in the cause of PE teaching [6].

Intellectual Property Rights. Intellectual property is the guarantee of innovation ability, the protection of intellectual property rights directly affects the ability of innovation. For the research on the innovation ability of physical education teaching, the strength of the protection of intellectual property is analyzed here [7].

Market Demand. The main innovations of sports teaching in various colleges and universities for its innovative research here will be recognized, recognition results of definition of innovation acceptance rate of innovation in the market, the various colleges and universities recognized said market acceptance rate [8]. Market acceptance rate will have a direct impact on scientific research funds and other means of financial support.

\section{Model Establishment}

In this paper, the system dynamics is used to study the. Because the sports teaching innovation ability involves the scope is broad, therefore needs to carry on the hypothesis first:

The hypothesis that the innovation ability of physical education teaching is influenced only by the infrastructure and scientific research personnel;

The hypothesis that the funding of teaching innovation ability of physical education is all summed up as research funding and research infrastructure, other funds are not considered;

It is assumed that the innovation ability of physical education teaching can be promoted;

The hypothesis that scientific research personnel only two categories of social research personnel and College Physical Education practitioners;

The Teaching Innovation Ability of Physical Education Research Funding Loop. Sports research funding is mainly aimed at sports research funding in the innovation of college students, through the research and production of funds for sports teaching in the use of links to study the innovative ability of physical education. In the funds arising from the use of links, investment, scientific research funds, universities and research institutes government research fund loan amount plays a main role, and produced a circular effect, the specific situation is shown in Fig 1. It can be found that there are two positive feedback loops in the causality diagram of scientific research funds: Sports teaching innovation ability $\rightarrow$ innovation achievement $\rightarrow$ innovation achievement transformation $\rightarrow$ government research funds investment $\rightarrow$ university scientific research fund $\rightarrow$ Sports teaching innovation ability. Sports teaching innovation ability $\rightarrow$ innovation achievement $\rightarrow$ loan scale of financial institutions $\rightarrow$ scientific research institutions $\rightarrow$ scientific research funds $\rightarrow$ scientific research funds in universities $\rightarrow$ scientific research institutes $\rightarrow$ teaching innovation ability. 


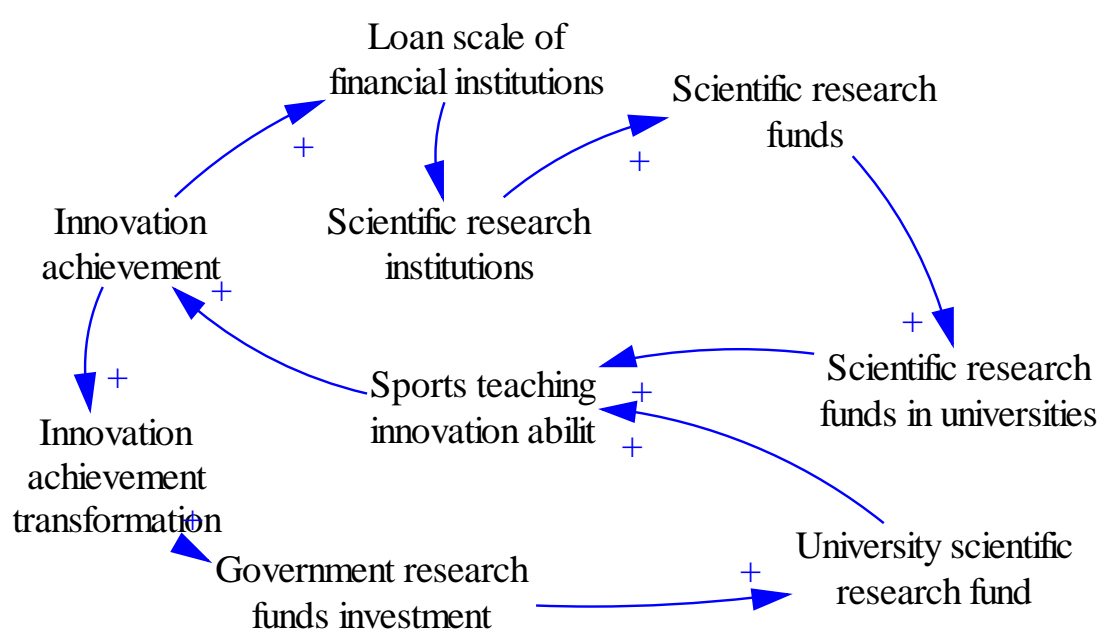

Fig.1 Causality diagram of scientific research funds

The Teaching Innovation Ability of Physical Education Research Personnel Circuit. The innovation ability of PE researchers plays an important role in the innovation of physical education teaching. The teaching innovation ability factors of physical education staff affect the innovation of physical education, and then affect the whole cycle process. Scientific researchers in the physical education teaching innovation ability will affect the achievement of innovation, innovation will attract social researchers, social researchers increased the number of researchers, and scientific research personnel increase will affect the scientific researchers in the physical education teaching innovation ability. Similarly, the teaching innovation ability of sports researchers will affect the scientific research achievements and university teaching innovation ability, and ultimately will affect their own. The main cycle is shown in Fig 2.From the above, we can find that there are 3 positive feedback loops in the causality diagram of the scientific research personnel: Sports teaching innovation ability $\rightarrow$ innovation achievement $\rightarrow$ social research personnel $\rightarrow$ the number of scientific research personnel $\rightarrow$ the introduction of scientific research personnel $\rightarrow$ sports teaching innovation ability; Sports teaching innovation ability $\rightarrow$ innovation achievement $\rightarrow$ scientific research ability $\rightarrow$ key university physical education teaching staff $\rightarrow$ the number of scientific research personnel $\rightarrow$ the introduction of scientific research personnel $\rightarrow$ sports teaching innovation ability; Sports teaching innovation ability $\rightarrow$ innovation achievement $\rightarrow$ key university graduates $\rightarrow$ college sports teaching staff $\rightarrow$ the number of scientific research personnel $\rightarrow$ the introduction of scientific research personnel $\rightarrow$ sports teaching innovation ability; From the feedback, it can be found that the focus of college sports teaching practitioners by the impact of scientific research ability and the focus of College graduates. The ability of scientific research is on the impact of professionals in sports teaching research level and cognition of the sports teaching work, and graduates of key universities is influencing the number of sports teaching practitioners, both universities have influence and teaching practitioners. Similarly, the numbers of scientific research personnel are composed of social researchers and University researchers, here are the assumptions of the scientific research personnel for sports teaching practitioners.

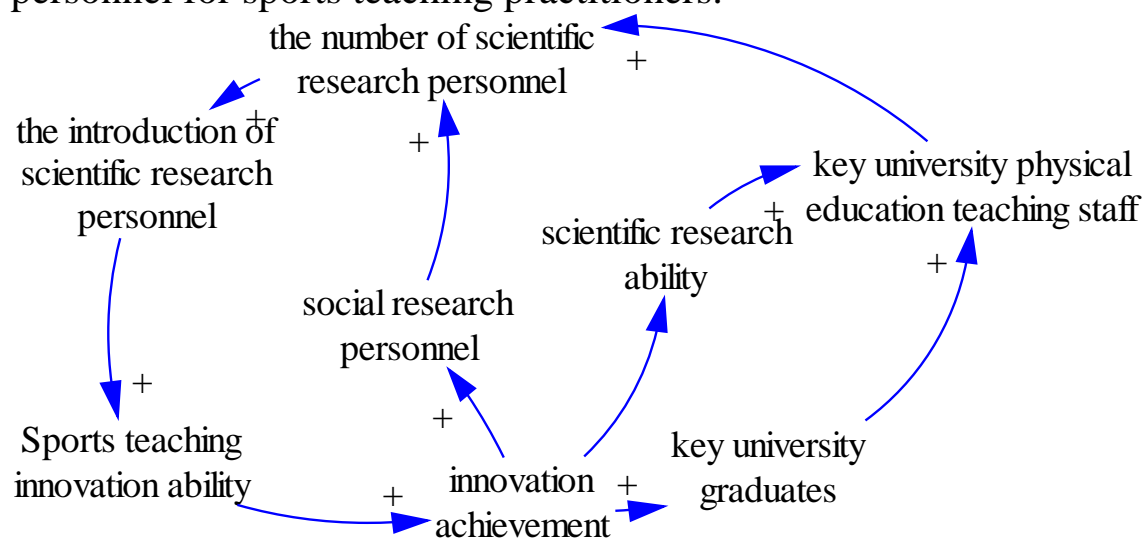

Fig. 2 Causality diagram of teaching innovation ability 
The Intellectual Property of the Innovation Ability of Physical Education Teaching. The innovation ability of physical education teaching of intellectual property will affect the individual awareness of protection for intellectual property rights, thereby increasing the protection of national strategy for intellectual property rights, the protection of intellectual property rights more rigorous, it will increase the teaching of physical education scientific research level, the specific cycle as shown in Fig 3.Intellectual property factors include a causal loop: Sports teaching innovation ability $\rightarrow$ innovation $\quad$ achievement $\rightarrow$ national innovation system innovation achievement $\rightarrow$ intellectual property value strategy factor $\rightarrow$ intellectual property protection strength $\rightarrow$ sports teaching innovation ability. The result of innovation has a direct impact on the results of national innovation system.

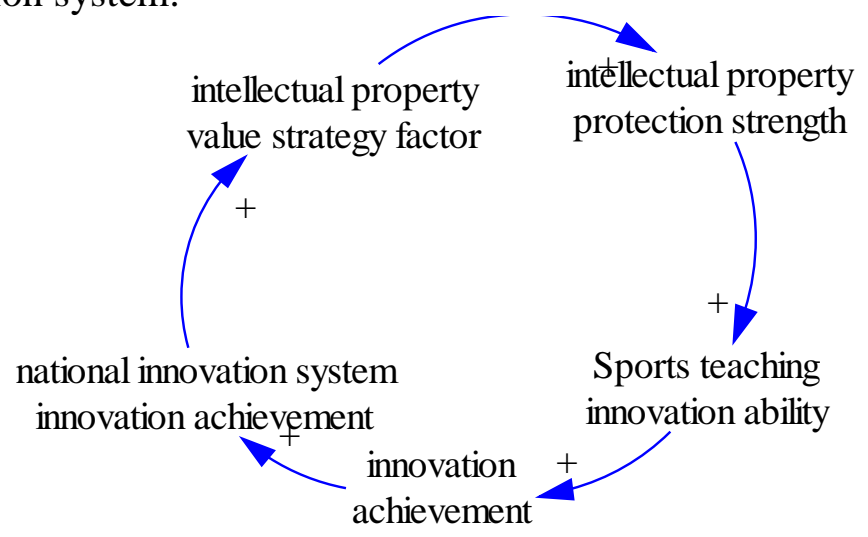

Fig.3 Causality diagram of intellectual property

The Market Demand Model of Innovation Ability in Physical Education Teaching. The results of scientific research need to determine the pros and cons according to the needs of the market. If the current market for sports teaching innovation results are very demanding, then there will be many researchers to study the innovation of physical education. Its specific cycle as shown in Fig 4. Market demand causality diagram contains a causal loop: Sports teaching innovation ability $\rightarrow$ innovation achievement $\rightarrow$ innovation achievement transformation $\rightarrow$ innovation achievement product $\rightarrow$ innovation achievement product market acceptance rate $\rightarrow$ Financing $\rightarrow$ Sports teaching innovation ability. The funds here refer to all the factors involved in the circuit diagram of the scientific research funds. Innovation achievement product market acceptance rate refers to the application of innovative achievements in the teaching of physical education innovation.

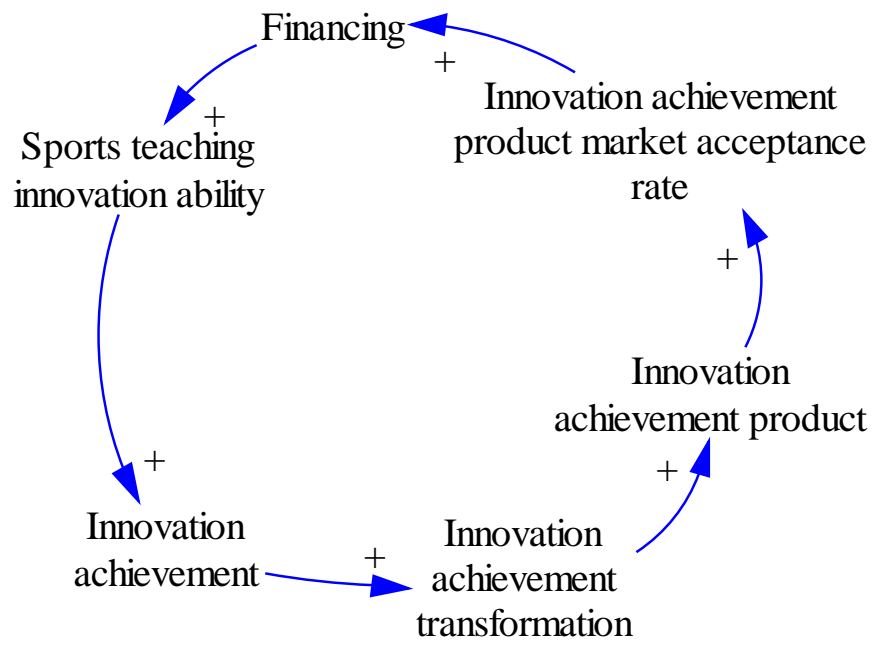

Fig.4 Causality diagram of market demand

\section{Analysis on the Innovation Ability of Physical Education Teaching under the Multi Objective Dynamic Condition}

Through the causal loop subsystem, construct the comprehensive causal loop diagram of the 


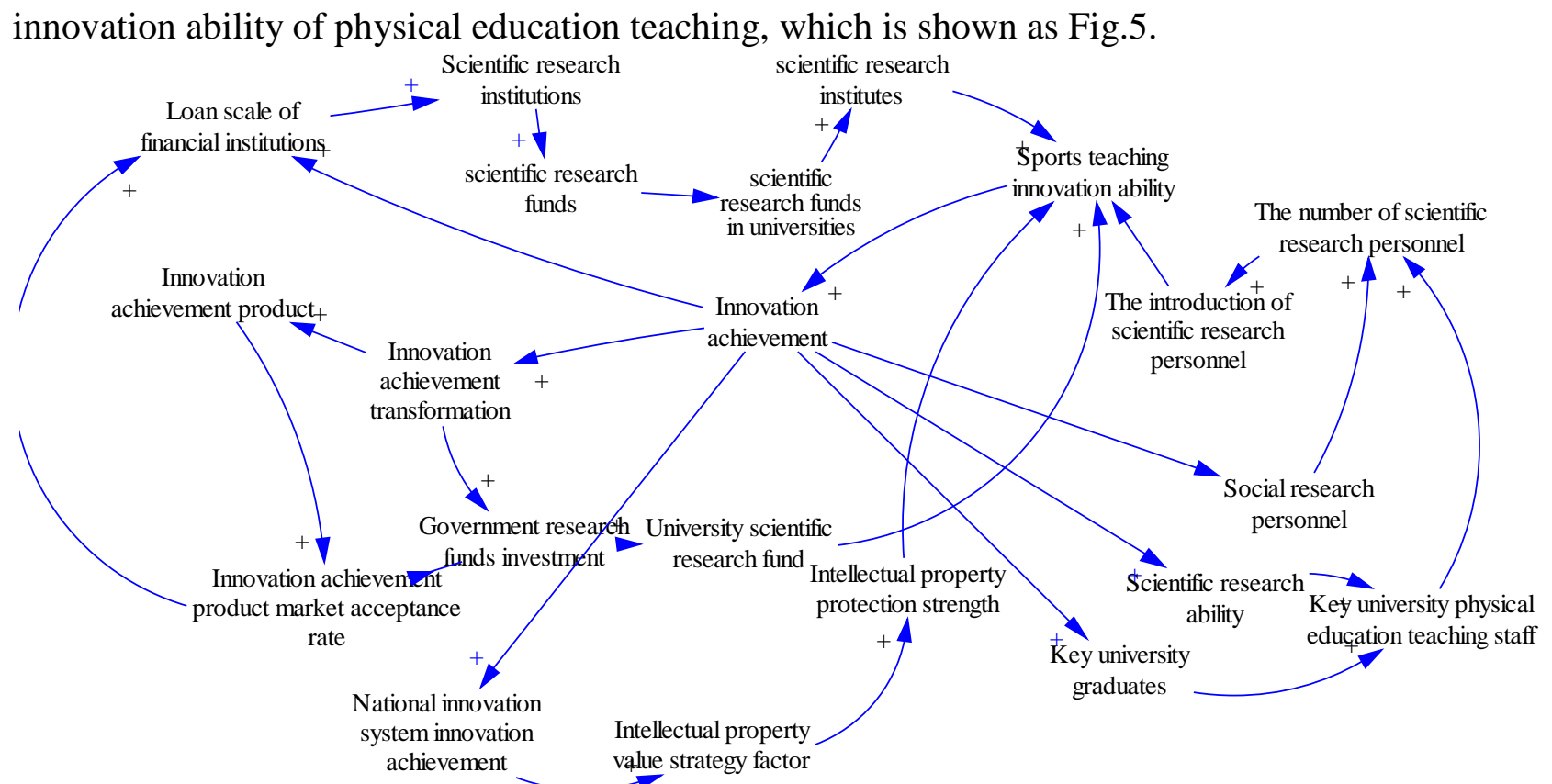

Fig.5 Causality diagram of PE teaching innovation ability

Introduction to the main formula:

(1) Sports teaching innovation ability $=$ scientific research personnel introduction $*$ coefficient + scientific research technical facilities * coefficient + intellectual property protection strength * coefficient + University Scientific Research Fund * coefficient (the coefficient here refers to the weight).

(2) Innovation achievement $=$ physical education innovation ability * coefficient (here coefficient refers to the average success rate of sports teaching innovation ability).

(3) Innovation achievement transformation $=$ innovation achievement $*$ innovation achievement conversion rate.

(4) The number of scientific research personnel $=$ social research personnel $*$ coefficient + key university sports teaching practitioners * coefficient (social research personnel coefficient is less than the key university sports teaching career personnel).

(5)The government investment in research funding = innovation achievement transformation rate * innovation results of the impact of the * coefficient + innovation achievement market acceptance rate * the benefits of innovation.

(6) The scale of loans of financial institutions = innovation achievement transformation rate * innovation results bring market benefits.

(7) The policy of intellectual property rights = national innovation system innovation achievement $*$ intellectual property policy factor.

(8)Intellectual property protection intensity $=$ intellectual property policy factor * coefficient.

(9)The total number of key university graduates $=$ the total number of colleges and universities * coefficients.

(10) Key university sports teaching staff = key university graduates * key university graduates engaged in the number of sports teaching professional number of * research ability * coefficient.

According to the 4 causality diagrams, we construct Fig 5: the total causality diagram of PE teaching innovation ability. It mainly expresses the factors that influence the innovation ability of $\mathrm{PE}$ Teaching in the whole cycle. And the formula is given for causality diagram. By the above formula and the system dynamics causality diagram, we can find that the innovation ability of physical education is mainly restricted by the hardware facilities and funds, as well as the scientific research personnel. At the same time, some of the country's policies will also affect the development of the innovation ability of physical education teaching. Hardware facilities is essential for the sports teaching ability, especially the innovation of physical education teaching the need for large-scale data collection and experimental teaching, the need to use some large 
equipment and experimental equipment to measure the teaching innovation of the students' physical quality and the quality of teaching. Funds is the most important development of sports teaching innovation ability, there is no support for funding, the experimental material and some of the methods of the experiment cannot be achieved perfectly.

\section{Conclusion}

Through the research on innovation ability of physical education teaching, innovation ability and development of PE teaching requires the support of the school, only the support of the school physical education teachers, to emancipate the mind and renew ideas, and improve physical health of students, from the perspective of learning, teaching methods to find the optimal search. Secondly, the development of the innovation ability of physical education needs a lot of financial support. Study every innovation will require substantial funds for support, the only way to follow the scientific research personnel in sports teaching of fitness, diversity and selectivity principle, can proceed from the overall teaching, optimize the combination, from a large number of experimental data, the future development of the students as the basis, integrated screening. Any research on the ability of innovation can not be separated from the support of the state, the state's policy support for the sports teaching and research personnel are supported. So the development of sports teaching innovation ability, from the school support, financial support and national support three aspects to expand, only in this way, can we develop the innovation ability of PE teaching.

\section{Acknowledgements}

This research is supported by ministry of education of humanities and social science research project: $<<$ Guided by professional core ability and core values of higher vocational physical education curriculum construction and promote research in xinjiang>> (14XJJA890001)

\section{Reference}

[1] RINK J. Designing the Physical Education: Promoting Active Lifestyle[M]. New York, NY: McGraw Hill-Higher Education,2007.15

[2] KLOEPPEL T,KULINNA P H,STYLIANOU M, et al. Teacher fidelity to one physical education curricular model[J]. J Teach Phys Edu,2013,32(2):186-204

[3] Shi Yan, Lei Aili. The comparative study of Chinese and foreign sports teaching mode and the lack of the construction of Chinese physical education teaching model[J]. Journal of Shenyang Institute of Physical Education, 2005,24(10):89-92

[4] PAN Ling-yun, Wang Jian. A comparative analysis of the teaching mode of contemporary sports -the lack of teaching mode construction of contemporary sports in China[J], Journal of Shandong Physical Education Institute, 2001,17(4):53-55

[5] Xu Ke, Construction of evaluation system of innovation capability of high tech Zone -- Based on system dynamics[J], Global market information.2015,15

[6] Liu Fengchao, Feng Tingting, System dynamics model and its application in the formation of national innovation ability, Science Research Management, 2011,8(32):17-24

[7] CHEN Lin-hua, WANG Yue, LI Rong-ri, DU Mei, WANG Yan, Research on the construction of evaluation index system of International Sports City, China Sport Science,2014(34):34-41

[8] SHI Yan, Opportunities and challenges faced by sports industry development in China under the background of new policies launched by the State Council for the sports industry, Journal of Physical Education,2014,11(21):14-18. 